\title{
REPRESENTAÇÃO DA CULTURA ESPORTIVA E DA MÍDIA EM MOÇAMBIQUE NA PERSPECTIVA DO DESENVOLVIMENTO HUMANO
}

\author{
Cláudio da Silva Tonetti \\ Mestre em Educação Física pela Universidade Federal de Santa Catarina.
}

Giovani de Lorezi Pires

Professor do Departamento de Pós Graduaçao em Educação Física da Universidade Federal de Santa Catarina.

\begin{abstract}
Resumo
Este artigo $^{1}$ teve por objetivo definir estratégias de intervenção sob a forma de políticas públicas. Para tanto, usou-se a abordagem observacional-descritiva, composta por: aplicação de inquéritos estruturados com realização de entrevistas individuais, análise observacional e elaboração de diário de campo. Os sujeitos da pesquisa foram: ex-atletas (GEX) e esportistas do lazer (DL). Realizou-se uma análise situacional do espaço esportivo de lazer e análise de conteúdo dos programas desportivo na mídia moçambicana. Em síntese, concluiu-se que a mídia é elemento fundamental que pode favorecer articular e harmonizar componentes do desenvolvimento humano e cultura esportiva em Moçambique.

Palavras-chave: Mídia - Cultura esportiva - Desenvolvimento Humano.
\end{abstract}

\section{Introdução e apresentação}

$\mathrm{O}$ interesse que move esta pesquisa é resultante das indagações originadas a partir do envolvimento com o trabalho de mídia esportiva, que abriu a possibilidade para a reflexão mais aprofundada sobre de que forma as representações da cultura esportiva estariam relacionadas ao desenvolvimento humano e qual a constituição que a mídia poderia ter nesta inter-relação em Moçambique, de modo a contribuir para a definição de estratégias de intervenção sob a forma de políticas públicas que, pautadas pela realidade da cultura esportiva em Moçambique, fossem implementadas por entidades nacionais e estrangeiras. Pode-se levantar alguns elementos da realidade moçambicana e seu conjunto de especificidades ao gerar interações positivas na trilogia: desenvolvimento humano, cultura esportiva e mídia, contribuindo na constituição de recomendações que possam ser viabilizadas na prática, e como subsídio e fator de reflexão na mídia esportiva em Moçambique.

Moçambique está situado na região austral da África. Alcançou sua Independência Nacional a 25 de junho de 1975. Possui uma superfície de 801.590 quilômetros quadrados, faz fronteira a Norte com a Tanzânia, a Leste com o Malawi, Zâmbia, Zimbábwe e a Sul com a Swazilândia e a África do Sul. A população está estimada em 20.069.738 milhões de habitantes segundo censo de 2007 realizado pelo Instituto

1 Baseado na Dissertacão de Mestrado apresentada para obtenção do título de Mestre pela UFSC (TONETTI, 2009). 
Nacional de Estatística (INE). A situação geográfica e a história deste país, marcada por vários processos migratórios, resultaram num grupo populacional heterogêneo, com características multiculturais e multiétnicas. Moçambique tem uma população predominantemente rural, com uma percentagem de 23\% dos habitantes em áreas urbanas. (CENSO, 2007). A economia moçambicana é basicamente agrícola (80\%). Moçambique é um dos países menos desenvolvidos do mundo, em 2007 foi colocado na 177 a posição, com um índice de 0,354 (PNUD², 2004). Cerca de $37,9 \%$ da população vive com menos de US\$1/dia e 78,4\% vive com menos de US\$2/dia (PNUD, 2004). Em 2002, o Produto Interno Bruto per capita (PIB ${ }^{3}$ ) cresceu cerca de $8 \%$ a partir da fórmula que agrega produto, renda e despesa. O PIB médio per capita é de 230 dólares (MOÇAMBIQUE, 2004) O orçamento do governo continua dependente da ajuda externa.

Maputo, a capital (ex-Lourenço Marques), no Sul do país, e a cidade da Beira, no centro, têm os mais elevados índices de concentração de população urbana, representando o imenso mosaico cultural que é Moçambique. A língua oficial é o Português, embora declarado como língua materna de apenas $5 \%$ da população durante o censo de $1997^{4}$. A insegurança alimentar é um problema grave em várias regiões do país, devido às condições climáticas desfavoráveis para a agricultura. Mais da metade da população (53\%) sofre de desnutrição e $26 \%$ das crianças menores de cinco anos têm peso baixo para sua idade (PNUD, 2004).

O governo de Moçambique utiliza diversas estratégias de desenvolvimento humano no âmbito da educação, saúde, agricultura, dentre outros. No que se refere ao esporte, o governo moçambicano aprovou na Assembléia da República, com publicação em Boletim da República a Lei no 11/2002, a Lei do Desporto ${ }^{5}$, que ratifica que o acesso à educação física e à prática esportiva é um direito consagrado a todo cidadão, conforme Constituição da República ( $n^{\circ} 1$ do Art. 135). Dessa forma, a Lei estabelece o esporte como uma atividade social de interesse público, que contribui para a formação e desenvolvimento integral do ser humano, melhoria da sua qualidade de vida e bem estar individual, coesão social, nacional e internacional, e institui a promoção e a orientação da prática esportiva 6 .

A cultura esportiva opera no imaginário individual e coletivo, quando é representado como promessa de felicidade, ascensão social, marketing pessoal, domínio tecnológico, reconhecimento nacional e afirmação política de determinado país ou

2 Programa das Nações Unidas para o Desenvolvimento

3 O PIB representa a soma (em valores monetários) de todos os bens e serviços finais produzidos em uma determinada região (qual seja, países, estados, cidades), durante um período determinado (mês, trimestre, ano, etc). É um dos indicadores mais utilizados na macroeconomia com o objetivo de mensurar a atividade econômica de uma região. Na contagem do PIB, considera-se apenas bens e serviços finais, excluindo da conta todos os bens de consumo intermediários (insumos).

4 Os dados preliminares divulgados pelo INE com relação ao censo de 2007 não apresentaram estas variáveis analisadas de forma desagregada. Por este motivo utilizou-se os dados consolidados e disponibilizados do ano de 1997.

5 Retirado do Boletim da República, 29 de março de 2004: Série I - Número 12.

6 A Lei do Desporto é composta por um conjunto de medidas legislativas, que tem por objetivo a criação de base para possibilitar o desenvolvimento do esporte visando o reconhecimento, promoção e o estímulo de outros atores sociais que se envolvam no movimento esportivo. 
ideologia. A mídia, a cultura esportiva e o desenvolvimento humano poderão constituir-se numa trilogia importante ao país, particularmente devido ao fator multiplicador desse potente veículo de comunicação que é a mídia. Entretanto, em Moçambique os habitantes que vivem nas regiões mais recônditas não têm acesso à mídia na sua totalidade, sendo nesse caso o rádio o mais importante veículo de comunicação. $\mathrm{O}$ fato de poucos terem acesso à televisão nos permite acreditar que uma maior difusão dos veículos midiáticos poderá contribuir no desenvolvimento humano dos moçambicanos, âmbito no qual as relações e influências da cultura esportiva ainda estão em formação.

Num país onde um campo de futebol (geralmente, sem as dimensões oficiais) pode ser encontrado em qualquer distrito (interior) e em que é apenas necessária uma bola para ir à busca de "talentos" (e não só) que abundam fora dos grandes centros urbanos, o esporte poderá desempenhar seu papel maior, particularmente nas regiões onde o nível de desenvolvimento humano é mais baixo. Contudo, a influência da cultura esportiva na perspectiva do desenvolvimento humano promovida pela mídia poderia ser uma forma de intervenção no combate à pobreza absoluta.

Para Bourdieu (1983), o esporte é um fenômeno de múltiplas dimensões, que tem correlação com os fenômenos políticos, econômicos, culturais e sociais. O esporteespetáculo exerce influência direta na sociedade por estar imerso em transformações e desenvolvimentos dos fenômenos citados anteriormente, mantendo, no entanto, suas características autônomas com os diferentes "recortes" possíveis. Esta relação mídia e cultura esportiva são relevantes, sobretudo quando se considera a vocação da mídia como um agente de comunicação que se utiliza de vários instrumentos para a difusão de suas mensagens e imaginários a um determinado público. A partir do entendimento de que o esporte é um produto histórico e cultural e que sobre este são atribuídas diferentes significações, pode-se afirmar que não existe a "História do esporte", mas que muitas histórias são possíveis de serem narradas e que dependem não apenas do referencial teórico que orienta o olhar de quem narra, mas, fundamentalmente, da qualidade das fontes acessadas, como referido por Goellner (2004).

De modo geral, este estudo visa, a partir de alguns dados analisados, contribuir para a definição de estratégias de intervenção sob a forma de políticas públicas que são pautadas pela realidade da cultura esportiva em Moçambique. E pode também servir de referencial para que a mídia local perceba e incentive a cultura esportiva como fator impulsionador de desenvolvimento humano, sabendo da existência da grande empatia da sociedade moçambicana em relação ao esporte nacional, que é o aglutinador de massas na busca da coesão nacional, ao construir e identificar simbolismos para a identidade nacional.

Em face do que foi, até agora, contextualizado e justificado, pode-se resumir a situação-problema na seguinte pergunta de partida: Como a mídia esportiva é percebida e representada nas camadas jovens e adultas com diferentes formações de cultura esportiva, e como este fato pode estar relacionado ao desenvolvimento humano em Moçambique?

Ao se considerar a pergunta de partida e o objetivo da pesquisa, formularam-se algumas questões de investigação que nortearam os passos da pesquisa.

- Quais são as características (freqüência, conteúdo, duração e alcance) de programas de mídia esportiva na televisão moçambicana? 
- Quais são as características (freqüência, conteúdo, duração e alcance) de programas de mídia esportiva na televisão moçambicana?

- É estabelecido nestas programações algum tipo de relação entre o esporte e aspectos gerais do desenvolvimento humano das comunidades ou grupos sociais envolvidos com a cultura esportiva?

- Como os sujeitos pesquisados expressam suas representações sociais a respeito dessa programação?

- É possivel afirmar que as práticas esportivas sofrem ou sofreram algum tipo de influência do discurso midiático-esportivo

- Será que eles atribuem alguma relação entre suas vivências esportivas com aspectos do desenvolvimento humano no contexto em que vivem e praticam esporte?

\section{Conceitos trabalhados}

Partindo da premissa de que a cultura é, ao mesmo tempo, determinante e determinada pelo estágio de desenvolvimento de um país ou sociedade, é possível considerar que o desenvolvimento está ligado às diversas dimensões da cultura e, neste caso, especialmente à cultura esportiva.

A cultura esportiva encontra-se enraizada nas mais diversas manifestações de alegria ou de tristeza de uma sociedade, produzindo uma riqueza diversificada de valores culturais e sociais. Nesse sentido, a cultura esportiva e as suas diversas manifestações, seja de lazer, aventura, de alto rendimento, amador, (tele) espectador, multidões e até no cotidiano, do dia a dia de cada um de nós, tem um sentido de relação umbilical amplo ou de uma via com "mão dupla" com o desenvolvimento humano de uma região, etnia ou país. Contudo, cada uma delas possui especificidades, representando um papel relevante na definição da política governamental de um país e contribuindo para o melhor desempenho administrativo na melhora de seus indicadores sociais.

Cabe ressaltar que as relações entre a cultura esportiva e o desenvolvimento humano de cada povo são reconhecidas, porém as diferenças se fazem sentir na história ou trajetória social de cada sociedade; especialmente em Moçambique, ambas contribuem como alternativas ou até mesmo como solução das várias situações adversas encontradas.

Se a cultura esportiva e o desenvolvimento humano são parte integrante das sociedades, pois "alimentam-se" uma da outra, numa relação de interdependência, o que pretendemos destacar aqui é o papel de ambos no crescimento econômico e educacional de um país ou região. Ao considerarmos ambos como uma estrada com sentido de "mão dupla", acredita-se que muitas vezes cruzam-se em busca de respostas para um melhor desempenho de uma sociedade ou povo, contribuindo no combate à fome, doenças, miséria, educação e também no melhoramento de outros valores positivos que podem construir a busca do progresso e estabilidade de uma região, etnia ou país. Assim, o desenvolvimento humano torna-se um dos alicerces de maior expressão no meio político, o que leva à preocupação de gerações e gerações, num constante estudo de suas causas e conseqüências, principalmente em países do terceiro mundo.

A cultura esportiva exerce um importante papel no desenvolvimento humano, tanto diretamente - na saúde, educação, renda, habitação, entre outros - pois serve de 
alternativas de ocupação profissional, quanto indiretamente, na formação política em suas diversas formas de representatividade, que promove a busca por melhores condições de inclusão nas sociedades, qualidade de vida, dignidade, respeito, promoção de emprego e muito mais.

Nesse sentido, vale afirmar que baixos níveis de desenvolvimento humano implicam a formação de uma pobreza política (DEMO, 2001), que leva a um estado perverso de conformação com as desigualdades e injustiças sociais, um determinismo que leva, muitas vezes, a aceitá-las sem questionamento, principalmente no que se refere à distribuição de renda e das riquezas produzidas pela sociedade. Enfim, as oportunidades de vida são escassas em países do terceiro mundo. Nesse viés, a pobreza política pode ser reconhecida como um elemento que permite observar possíveis variações nas condições sociais de uma dada sociedade, acreditando-se que ela seja uma fase de transição, passível de transformação.

Interessa agora observar que, junto ao que chamamos de via de "mão dupla”, em que percorrem o desenvolvimento humano e a cultura esportiva, encontramos uma "auto-estrada" de grande velocidade que é a mídia, com grande efeito aglutinador na formação de opinião e até mesmo na tomada de decisões de outros agentes condutores da cultura, como é o caso das elites, escolas, governos, etc. Graças à grande capacidade de difusão e abrangência, a mídia se constitui num importante vetor na formação de valores, educação, promoção da liberdade, cooperação, solidariedade, ética, entre outros. A mídia tem ligação mais eficaz e direta com a cultura esportiva porque ambos são formadores e difusores das mais diversas formas de opinião, muitas vezes até alertando os governos, escolas, clubes, das diferentes concepções do país e do mundo.

Ao identificarmos essa trilogia, podemos perceber o papel da mídia no status quo da cultura esportiva, que, por sua vez, liga-se ao desenvolvimento humano. Percebe-se então que a cultura esportiva pode ser tomada como uma das pontes entre a mídia e o desenvolvimento humano, mesmo sabendo que, muitas vezes, a mídia pode também intervir diretamente junto ao desenvolvimento humano. Podemos, assim, preconizar a importância da mídia na concepção de idéias, opiniões e formação de identidades, num caminho que, ao passar pelo campo da cultura esportiva, enraíza estes valores numa estrutura social que transmite significados socialmente relevantes às informações veiculadas pela mídia. Podemos perceber, então, que a mídia tende a contribuir na articulação das membranas sociais e esportivas, na construção do desenvolvimento de uma nação.

A mídia pode mostrar o país real dentro das conjunturas atuais de cada um, de forma transparente, contribuindo assim para o desenvolvimento humano e traz, de certa forma, a representatividade das culturas e, neste caso, especialmente a esportiva, como forma de contribuir para identidade moçambicana.

Logicamente, o discurso da mídia não é unívoco nem linear. Pelo contrário, a sua complexidade e o jogo de interesses que o conformam exigem um modo de lidar com elementos críticos.

\section{Metodologia}

Esta pesquisa apresentou uma abordagem observacional-descritiva do objeto de estudo, tentando compreender suas características intrínsecas e conjunturais, que se 
constituíram nos dados coletados no campo. A metodologia de análise dos dados escolhida foi a qualitativa, que oferece a possibilidade de utilizar uma variedade de procedimentos e instrumentos de coleta de dados. Foi utilizada a entrevista semiestruturada (ou entrevista com roteiro), por ser considerada apropriada para a coleta de depoimentos pessoais. A pesquisa qualitativa, segundo Goldenberg (2001), está embutida na questão da possibilidade (ou não) de sua generalização, preocupação primeira do modelo das ciências naturais, que se impõe como paradigma.

Para interpretação dos dados, o procedimento metodológico utilizado foi a análise de conteúdo, que é, segundo Bardin (1979, p. 42), "um conjunto de técnicas de análise de comunicação, através da descrição do conteúdo das mensagens produção e recepção obtendo indicadores quantitativos ou não que permitem a inferência de conhecimentos relativos às condições de produção/recepção das mensagens."

A análise de conteúdo permitiu a interpretação de textos podendo partir de uma perspectiva quantitativa, analisando numericamente a freqüência de ocorrência de determinados termos, construções e referência. A análise contribuiu na aferição das entrevistas que foram realizadas, e que permitiu construir um conhecimento, ao analisar o discurso, a disposição e os termos utilizados pelos inquiridos da pesquisa.

O processo de categorização, do tipo empírico, possibilitou a utilização das entrevistas semi-estruturadas, com o agrupamento de respostas por afinidade específica, permitindo a organização temática dos resultados das entrevistas. Essa análise facilita a utilização do recurso de triangulação, e da prática de confrontação de variadas evidências sobre o mesmo fenômeno, permitindo a comparação dos relatos.

De modo concreto, após a sistematização os dados, eles foram submetidos à préanálise, exploração e tratamento dos resultados, a partir da técnica de exaustão. Esta técnica é conhecida por buscar similaridades nas respostas, e muitas vezes as tendências de respostas encontradas não permitem obter dados novos.

Apresentamos o processo de constituição das categorias empíricas e teóricas, e articulação da operação de classificação de elementos constitutivos de um conjunto, por diferenciação e, depois, por reagrupamento do gênero com critérios previamente definidos. Isto é, "a análise de conteúdo assenta implicitamente na crença de que a categorização (passagem de dados brutos a dados organizados) não introduz desvios (por excesso ou por recusa) no material, que nos dá a conhecer índices invisíveis, ao nível dos dados brutos" (BARDIN, 1979, p. 119).

A pré-análise consistiu em organizar o material que obtivemos durante a pesquisa empírica, ou seja, descrição analítica. Na segunda etapa, exploração e tratamento dos resultados foram submetidos à interpretação aprofundada e orientada através de um estudo, e, na terceira etapa, estabelecemos reflexões e relações do estudo efetuado. Em todas estas etapas estudamos de uma forma sucinta o processo de análise de conteúdo, conforme Trivinos (1987).

A primeira etapa foi a descritiva, de modo a enumerar as características do campo, após tratamento, seguindo-se a etapa da interpretação, na qual atribuímos significados às características encontradas, e, por último, a inferência que vem a partir de um procedimento intermediário, explícito e controlado. Podemos, a partir destas informações, observar os possíveis efeitos das mensagens (entrevistas) e o que elas provocaram a partir de deduções lógicas sem, contudo, obtermos uma solução para a pesquisa. 
O papel do pesquisador foi fundamental e subjetivo, a sua percepção foi tanto mais apurada por sua vivência no ambiente em que os objetos de estudo foram enquadrados, no âmbito dos esportistas do lazer e dos ex-atletas, que se constituíram como sujeitos desta pesquisa.

Os grupos pesquisados foram constituídos por ex-atletas (grupo denominado a partir daqui de GEX) composto por nove sujeitos, e por pessoas que praticam esporte no tempo livre, denominados de esportistas de lazer (compondo o grupo representado pela sigla EL) constituídos por seis moçambicanos. Tais grupos se justificam por se entender que eles compreendem amplo espectro de possibilidades de relacionamento com as três componentes desta pesquisa. Apropriamos conceitualmente da Teoria das Representações Sociais, por entendermos que os depoimentos colhidos nos ajudaram a compreender como é representada em Moçambique a idéia de desenvolvimento humano/social, permeada pelo esporte e pela mídia esportiva.

Daí a importância de o pesquisador conhecer o contexto e a própria história de vida de muitos dos sujeitos da pesquisa. Ainda no plano metodológico dos estudos das representações sociais, distinguem-se as observações empíricas realizadas pela ausência de validação quantitativa do material simbólico coletado, o que resulta na ênfase, entre outras abordagens quantitativas, na análise de conteúdo, procedimento que ajuda na descrição de dados simbólicos a partir de unidades de registro do texto. (SOUZA FILHO, 2004).

\section{Apresentação e discussão dos resultados}

A questão principal que este estudo se propôs responder foi de apresentar, mediante a exposição de elementos teórico-conceituais e práticos, como a mídia esportiva é percebida e representada nas camadas jovens e adultas com diferentes trajetórias e formações na cultura esportiva, e como este fato pode se relacionar diretamente ao desenvolvimento humano em Moçambique. A apresentação dos elementos produzidos serve para que possamos, junto com ela, sugerir algumas estratégias possíveis de intervenção.

Da análise efetuada, podemos afirmar que os espaços para o esporte na mídia moçambicana ainda são escassos e até restritos, em tempo de antena, que chegam a alcançar $15 \%$ do total de tempo de antena na semana ${ }^{7}$. Mesmo assim, é reconhecido que a abertura política e o processo de democratização, vivido pelo país, têm apresentado melhoras significativas, especialmente na qualidade das matérias e temas abordados na televisão, incluindo a veiculação de programas nacionais.

Contudo, no esporte, o acento é dado com maior ênfase ao futebol, quer seja com a transmissão de eventos internacionais ou mesmo nacionais. No que se refere à mídia, especialmente a televisiva, os entrevistados apresentam uma consideração de que ela precisaria veicular mais os eventos nacionais e dar um espaço aos assuntos que envolvam outras modalidades, nas localidades e comunidades moçambicanas mais distantes dos grandes centros urbanos.

7 Programação analisada se refere à Televisão Estatal de Moçambique, a TVM (Televisão de Moçambique). 
Esta sugestão trazida pelo grupo de entrevistados aponta a responsabilidade que a mídia possui quanto à popularização do esporte, na medida em que aumenta sua cobertura televisiva, mas também o compromisso referente ao desenvolvimento da cultura esportiva no país, junto aos telespectadores/participantes de maneira geral.

O envolvimento e participação na mídia, bem como a disponibilização das imagens, contribuem no fortalecimento da cultura esportiva no país, mas também agem diretamente sobre o desenvolvimento humano. Pois, a partir desse movimento participativo, o convívio, a integração dos grupos, o trabalho em equipe, a qualidade de vida e outros itens importantes no que entendemos por desenvolvimento humano, são abarcados.

Outro ponto ainda sobre a questão das características dos programas que pretendemos aqui tornar um aspecto de recomendação é que, na medida em que a mídia veicula imagens e reportagens sobre dada modalidade, ela contribui para sua divulgação e sua popularização. Deste modo, não podemos desconsiderar que uma questão que possibilita às pessoas optarem pela prática esportiva é o fato de terem/ obterem conhecimento e informação ${ }^{8}$. A valorização do esporte ou de um dado esportista é fato a ser questionado e pensado junto à mídia, foi aspecto relevante aos GEX não se referirem à contribuição que o esporte traz em termos de desenvolvimento humano e reconhecimento do país, mas exclusivamente ao aspecto de desenvolvimento pessoal, restringindo assim seu discurso à auto-nomeação de passarem a ser reconhecidos socialmente.

Moçambique é um país onde o esporte (profissional/rendimento) ainda está por ser consolidado, nas diferentes modalidades, porque possui as mais diferentes dificuldades que vão desde organização, infra-estrutura, políticas, entre outros. Há falta de esportistas profissionais, pois levando em conta a Lei do Desporto, na qual o profissional do esporte é aquele que exerce a atividade esportiva como profissões exclusivas ou principais, em Moçambique ainda não se teria como indicar tal existência já que o esportista tem de buscar outros meios para subsistência. Ou seja, essa Lei identifica a questão, mas não consegue ser propositiva em termos práticos, que possibilitem a operacionalização da profissionalização esportiva. Isto leva o esportista a entender sua prática como um hobby, com raras exceções de alguns clubes que movimentam a modalidade de futebol.

Dentro de tais considerações, é importante pensar que a mídia poderia e pode contribuir para a consolidação da cultura esportiva, tanto no lazer quanto na alta competição, através da promoção de debates, aumento de espaços para discussão sobre o lugar do esporte, favorecendo a questão do desenvolvimento humano, conforme dito anteriormente.

Dessa forma, superaria a mera valorização das individualidades e auto-promoções, para uma contribuição social mais efetiva que pode refletir na qualidade de vida da população, mas também na consolidação da cultura esportiva.

Como referido nas considerações teórico-conceituais que adotamos, a mídia tem um papel fundamental na construção de um espaço no qual possa haver discussões de assuntos e busca de soluções, pois como advoga Bourdieu (1997), os profissionais da mídia são produtores culturais do que se chama espaço público. Somado a isto,

8 A questão sobre o fenômeno da popularização do futebol na África a partir da cobertura da mídia é feita por Domingos (2006). 
podemos dizer que a mídia hoje dentro da sociedade globalizada, como refere Pires (2005), produz, difunde e por vezes até transforma as manifestações culturais esportivas. Ou seja, trazer uma discussão crítica junto à mídia sobre seu real papel e contribuição para consolidação do desenvolvimento humano e da cultura esportiva seria função primordial junto aos profissionais da mídia esportiva, em Moçambique.

Importante retomar a questão do espaço da mídia como espaço público, pois este é um dos pontos indicados pelos entrevistados, principalmente ao referirem à necessidade de que a mídia tornasse pública a real falta de espaços esportivos em Moçambique, e assim auxiliasse na discussão e encaminhamento desse problema. A discussão a ser pautada na mídia junto à sociedade civil em seus debates públicos, sobre isto, poderia encontrar eco na própria Lei do Desporto, a qual identifica como função do Governo a construção, manutenção, preservação, desenvolvimento e gestão de infra-estruturas esportivas, quer sejam para o esporte comunitário ou para o de alta competição.

Enquanto divulgador de informação, a mídia contribui para fortalecimento de aspectos sociais importantes e relevantes às comunidades, desde que o faça em prol do desenvolvimento da democracia e da participação do cidadão nos problemas de espaços, infra-estruturas entre outros, para prática do esporte. Essa questão foi muito presente nas entrevistas, mas também na observação do campo foi possível notar que mesmo os espaços existentes têm uma dificuldade real quanto a sua gestão, conservação e manutenção.

Há ainda confusão na demanda, isto porque temos de novamente dizer que se trata de um país que fez recentemente sua transição do colonialismo para o socialismo e mais recente ainda para a democracia. Com isto, ainda existe e está presente no discurso o Estado ou o Governo como sendo único responsável pela cessão, criação, manutenção dos espaços a serem utilizados para o esporte. Incluímos ainda que sejam muitas as federações e clubes que dependem unicamente das verbas governamentais para sua existência, ou seja, aqui tocamos em um ponto sensível que necessita ainda ser discutido e melhor aprofundado, e pode contribuir para que os aspectos da democracia reflitam o compromisso da sociedade civil e a responsabilização social de cada um dos cidadãos, com relação aos espaços que denominamos públicos, ou comuns.

A questão de ter a relação entre desenvolvimento humano e cultura esportiva passa hoje em Moçambique pela participação mais comprometida e com qualificação da mídia esportiva e mídias em geral. Esses espaços poderão inclusive promover o debate sobre a relação entre desenvolvimento humano e esporte. Isto porque, o senso comum ainda é de que o desenvolvimento se restringe ao bem estar físico, no caso dos DL, ou ainda aos aspectos de desenvolvimento financeiro e de auto-promoção como refletido nas entrevistas dos GEX. Vale lembrar que visamos trabalhar com um conceito mais ampliado de desenvolvimento humano, no qual o desenvolvimento humano está vinculado diretamente com a promoção e qualidade de vida, sendo as capacitações humanas um rol das possibilidades de acesso e oportunidades, que irão promover a capacidade de escolha de um caminho de vida possível, se constituindo como um suporte para propósitos culturais em sociedades pluralistas. Singularmente aqui, o objetivo principal é que o desenvolvimento de capacidades humanas e de potenciais estejam estritamente vinculados ao aumento de opções e possibilidades as quais uma pessoa possa ter acesso. 


\section{Considerações finais}

A partir dos relatos dos sujeitos pudemos perceber que, para ambos os grupos, o esporte, a mídia e o desenvolvimento humano contribuíram em suas trajetórias de vida, no sentido que abordamos, havendo, pois, a necessidade de poder ampliar esta discussão.

Sumarizando as reflexões sobre o estudo de campo, na perspectiva das questões de investigação, podemos afirmar, sem com isso, pretender uma generalização indevida, que:

A diferença de concepção do esporte entre os dois grupos de sujeitos entrevistados se reflete também na condição que conferem à mídia esportiva; assim, os GEX consideram que o fato dela fazer, prioritariamente, a cobertura do esporte de alto rendimento contribui para o desenvolvimento dessa dimensão da cultura esportiva e, portanto, dos seus atletas, tornando-os conhecidos e ídolos no país. Os DL não discordam da importância da cobertura midiático-esportiva do chamado alto rendimento, concordando que tal fato incentiva e massifica a prática do esporte, o que representa um benefício a toda a população, porém, estes sujeitos, coerentemente com sua opinião sobre a dimensão social e coletiva do desenvolvimento humano, também reclamam da ausência ou da reduzida presença dos esportes amadores e da discussão sobre políticas públicas de esporte e lazer na mídia televisiva;

Podemos inferir que a própria noção de desenvolvimento humano relacionado ao esporte e à mídia reflete essas diferenças: para os GEX, a cultura esportiva valorizada na mídia oportuniza o desenvolvimento no sentido mais individual, tomando os seus casos pessoais como referência para tal afirmação. Enquanto isso, os esportistas de tempo livre preocupam-se também com as condições de acesso e permanência na cultura esportiva de segmentos sociais que dependem das políticas públicas para isso;

Outro fato relevante que contribui para a diferenciação dos grupos da pesquisa é quanto ao papel atribuído ao esporte escolar. Se para os GEX a Educação Física e o esporte praticado no âmbito escolar não são lembrados como significativamente importantes para a construção da sua cultura esportiva e, portanto, seu desenvolvimento neste campo, para os DL é justamente o aprendizado educativo do esporte como conteúdo pedagógico da escola que faz com que eles tenham adquirido o conhecimento sobre a importância da prática regular do esporte como fator de desenvolvimento humano, por suas múltiplas facetas.

Finalizando estas considerações podemos dizer que a mídia é elemento fundamental que pode favorecer articular e harmonizar as componentes do desenvolvimento humano e cultura esportiva. A interação e inter-relação entre mídia, cultura esportiva e desenvolvimento humano seria indicativa e promotora de transformações no contexto social que poderiam contribuir em Moçambique para o que poderemos nomear com fortalecimento necessário para o Take off do esporte em Moçambique.

Representation of sport culture and media in mozambique on a human development perspective

\section{Abstract}

This article aims at defining intervention strategies in the form of public policies, by means of a descriptive-observational approach with the following procedures: semi-structured interviews, observational 
analysis, and field notes. Research participants were former athletes (GEX) and leisure sports people (DL). A situational analysis of leisure sport spaces and a content analysis of sports programs in Mozambiquean media. Results showed that media is a fundamental element which can help articulate and harmonize human development and sport culture components in Mozambique.

Keywords: Media - Sport Culture - Human Development

Representación de la cultura deportiva y los medios en mozambique en la perspectiva del desarrollo humano

\section{Resumen}

El artículo tuvo como objetivo definir estrategias de intervención bajo la forma de políticas públicas. Se utilizó el enfoque observacioneal descriptiva, compuesta por: aplicación de averiguaciones estructurados con realización de encuestas individuales, análisis observacional y elaboración de diario de campo. Los sujetos de la investigación fueron: ex-atletas (GEX) y deportistas del ocio (DL). Se realizó un análisis situacional del espacio deportivo de entretenimiento y análisis de contenido de los programas deportivos en los medios moçambicanos. En síntesis, se concluye que los medios son un elemento fundamental que puede favorecer articular y armonizar componentes del desarrollo humano y cultura deportiva en Mozambique.

Palabras-clave: Medios de Comunicación - Cultura deportiva - Desarrollo Humano

\section{Referências}

BOURDIEU, P. Como é possível ser esportivo. In: Questões de sociologia. Rio de Janeiro: Marco Zero, 1983. . Sobre a televisão. Rio de Janeiro: Jorge Zahar, 1997.

BARDIN, L. Análise de conteúdo. Lisboa: Edições 70,1979.

DOMINGOS, N. Futebol e colonialismo, dominação e apropriação: sobre o caso moçambicano. Analíse Social, Lisboa; n. 179, p.397-416, 2006. Disponível em:< http://www.scielo.oces.mctes.pt?script=sci_arttext\&pid=S00032573200600020000 4\&Ing=pt\&nrm=iso >Acesso em: 17. dez. 2008.

DEMO, P. Educação e conhecimento: relação necessária, insuficiente e controversa, 2 ed. Rio de Janeiro: Vozes, 2001.

GOLDENBERG, M. A arte de pesquisar: como fazer pesquisa qualitativa em ciências sociais, 5. ed. Rio de Janeiro: Editora Record, 2001.

GOELLNER, S. V. Esporte moderno: memória e história. Revista Digital, Buenos Aires, v. 10, n. 77, p. s/p, out. 2004. Disponível em:< http://www.efdeportes.com/ >. Acesso em: 16. ago. 2008

MOÇAMBIQUE. Boletim da República,v. 1, n. 1, 29 mar. 2004. (Documento oficial do Governo de Moçambique).

. Censo 2007. Resultados Preliminares do III recenseamento geral da população e habitação. Instituto Nacional de Estatística de Moçambique, 2007.

. Parpa. Editora. Assembléia da República. 2006.

PROGRAMA das Nações Unidas para o Desenvolvimento. ONU, 2004. 
PIRES, G. L. Cultura esportiva: dicionário crítico da educação física. In: GONZALEZ, F. J; FENTERSEIFER, P. E. (Orgs.). Dicionário crítico de educação física. Ijuí: Ed. UNIJUI, 2005.

SOUZA FILHO, E. A. de. Representações sociais da sala de aula através de desenhos de estudantes do ensino fundamental , público e privado do Rio de Janeiro, In: MOREIRA, A. S. P; CAMARGO, B. V. (orgs.). Contribuiçôes para a teoria e o método de estudo das representações sociais. João Pessoa: Editora Universitária da UFPB, 2004.

TONETTI, C. Representação da cultura esportiva e da mídia em Moçambique na perspectiva do desenvolvimento humano. Dissertação (Mestrado em Educação Física). Florianópolis: PPGEF/UFSC, 2009.

TRIVINOS, A. N. S. Introdução à pesquisa em ciências sociais: a pesquisa qualitativa em educação. São Paulo: Atlas, 1987.

Recebido em: 02 de abril de 2009

Revisado em: 13 de abril de 2009

Aprovado em: 30 de abril de 2009

Endereço para correspondência

claudio.tonetti@gmail.com. 